\title{
Mode I Interlaminar Fracture Toughness Analysis of Co-Bonded and Secondary Bonded Carbon Fiber Reinforced Composites Joints
}

\author{
Camila Belo Gomes Brito *, Rita de Cássia Mendonça Sales Contini ${ }^{a, b}$, Ricardo Francisco Gouvêa ${ }^{a}$, \\ Arthur Scaglioni de Oliveira ${ }^{b}$, Mariano Andrés Arbelo ${ }^{a}$, Mauricio Vicente Donadon ${ }^{a}$ \\ ${ }^{a}$ Departamento de Estruturas Aeroespaciais, Instituto Tecnológico de Aeronáutica - ITA, Pça. Marechal \\ Eduardo Gomes, 50, Vila das Acácias, 12228-900, São José dos Campos, SP, Brazil \\ ${ }^{b}$ Laboratório de Estruturas Leves, Faculdade de Tecnologia de São José dos Campos - FATEC-SJC, \\ Av. Cesare Mansueto Giulio Lattes, s/n ${ }^{\circ}$, Eugênio de Melo, 12247-014, São José dos Campos, SP, Brazil
}

Received: October 27, 2016; Revised: November 08, 2017; Accepted: December 23, 2017

\begin{abstract}
Aiming to reduce aircraft weight, aeronautic industry seeks alternative materials and processes used to join its different structural parts. An option to traditional methods are high performance adhesive joints, which reduce weight, number of parts and component final cost, also resulting in higher strength structures. Although, the lack of experimental data to provide a detailed structural characterization of these joining techniques had limited their commercial application. The proposal of this work is to investigate the Mode I interlaminar fracture toughness under quasi-static loading using DCB specimens of carbon composite joints made by co-bonding and secondary bonding techniques, the latter giving more reliable results. For a better understanding on the failure in the systems, DSC and microscopy techniques were applied, from which three stages of delamination process during testing were observed: $1^{\text {st }}$ Stage) Cohesive failure represented by an unstable crack propagation from a high energy level; $2^{\text {nd }}$ Stage) transition from cohesive to adhesive and final intralaminar failure mode with lower energy levels than Stage 1 ; and $3^{\text {rd }}$ Stage) completely stable propagation at low energy levels (delamination migrates from intralaminar to interlaminar, entirely in the substrate).
\end{abstract}

Keywords: Fracture toughness, Mode I, Co-bonded, Secondary bonded, Carbon fiber composites.

\section{Introduction}

In the last few decades, the use of composite materials in the aeronautic industry has grown, resulting in the development of aircrafts with higher structural performance and optimized manufacturing processes, decreasing fabrication time, costs and operational risks ${ }^{1}$. Such development is due to the advantages the use of these materials brings, like resistance to corrosion, fatigue, impact and thermal stability, besides the more attractive mechanical characteristics in comparison to metallic materials ${ }^{2}$ traditionally used.

Additionally to composite material itself, the study of alternative bonding techniques has also become a topic of relevance in the industry, taking place of the conventional screws and rivets, which not only increase weight but also deteriorate the components structural capacity because they actuate like a stress concentrator contributing to severe delamination problems ${ }^{3,4}$.

In this manner, co-cure, co-bonding and secondary bonding techniques have received special attention in recent years, with emphasis on the last two for allowing more varied project designs, sizes and simpler manufacture ${ }^{3}$, besides lowering or suppressing the stress concentration ${ }^{5}$. The difference between each of them is that in co-cure, two uncured laminates are cured simultaneously, in the presence of an adhesive or not. For secondary bonding, both laminates are already cured when the bonding is established by an adhesive that requires the system to return to autoclave to its cure. Lastly, co-bonding has only one of the laminates cured prior bonding, requiring the system to return to autoclave to cure the uncured laminate and the adhesive.

Nevertheless, a deeper understanding on the mechanical and failure behaviors of structures obtained using these new joining technologies is still needed in order to enable their use on applications of high structural loading, replacing the fasteners used in conventional designs. In this case, fracture toughness under Mode I failure $\left(\mathrm{G}_{\mathrm{IC}}\right)$, is one of the parameters to be evaluated in order to verify the reliability and certifiability of these new joining technologies ${ }^{3}$.

In the work of Blackman et al. ${ }^{6}$, for example, a polymeric composite reinforced with unidirectional carbon fiber IM7/977-2 manufactured by Cytec Fiberite ${ }^{\circledR}$, epoxy structural adhesive of general use and secondary bonding process resulted in 
the $\mathrm{G}_{\mathrm{I}}$ values of $151 \mathrm{~J} / \mathrm{m}^{2}(0.151 \mathrm{~N} / \mathrm{mm})$ (initiation) and $208 \mathrm{~J} / \mathrm{m}^{2}(0.208 \mathrm{~N} / \mathrm{mm})$ (propagation). In a complementary work, Blackman et al. ${ }^{7}$ studied the effects of water in the carbon fiber reinforced polymer plates prior to bond them by secondary bonding technique, which resulted in a $\mathrm{G}_{\mathrm{I}}$ of $202 \mathrm{~J} / \mathrm{m}^{2}(0.202 \mathrm{~N} / \mathrm{mm})$ for joints prepared with substrates that were not submitted to a previous conditioning.

Ashcroft, Hughes and $\mathrm{Shaw}^{8}$ reported a detailed study on $G_{I}$ characterization of secondary bonded joint samples produced from cured graphite fiber and matrix BMI/epoxy panels with a toughened epoxy adhesive film. According to the authors, the delamination process in this type of joint is dominated by a sequence of rapid growth and arrest phases, named stick-slip behavior. The authors related a different $G$ value for each phase observed in this phenomenon: $G_{i}$, that starts the rapid and unstable crack propagation (where light-fiber-tear failure is dominant) and $G_{a}$, that stops the fast crack growth when it is reached and initiates the phase of slow growth (with cohesive failure in the adhesive as the dominant failure mechanism). Therefore, $\mathrm{G}_{\mathrm{i}}$ was found to present values up to $400 \mathrm{~J} / \mathrm{m}^{2}(0.4 \mathrm{~N} / \mathrm{mm})$, while $G_{a}$ varies between $200-300 \mathrm{~J} / \mathrm{m}^{2}(0.2-0.3 \mathrm{~N} / \mathrm{mm})$. Throughout this work, the terms "stable propagation" and "unstable propagation" will refer to crack growing in a steady slow rate and in a fast unexpected manner, respectively.

In a work conducted by Moura, Campilho and Gonçalves ${ }^{9}$, $\mathrm{G}_{\text {Ic }}$ of $0.4 \pm 0.02 \mathrm{~N} / \mathrm{mm}$ was found for secondary bonding samples, composed of unidirectional carbon/epoxy prepreg (SEAL ${ }^{\circledR}$ Texipreg HS 160 RM) and Araldite ${ }^{\circledR} 2015$ adhesive, using the corrected beam theory for data reduction, same method used in this work.

To investigate the influence of manufacturing and inservice factors that may deteriorate the bonding quality of adhesively bonded composites for aeronautical applications, Markatos et al. ${ }^{10}$ loaded carbon/matrix T700/M21 from Hexcel ${ }^{\circledR}$ specimens on Mode I delamination tests considering different processes. For the reference samples, values of $1200 \mathrm{~J} / \mathrm{m}^{2}$ $(1.2 \mathrm{~N} / \mathrm{mm})$ were found, while the worst case, corresponding to a poor curing of the adhesive, condition defined by the temperature being kept below the one prescribed in the respective guidelines (resulting in a unfinished curing process), caused a decrease in the $G_{I}$ value under $100 \mathrm{~J} / \mathrm{m}^{2}(0.1 \mathrm{~N} /$ $\mathrm{mm})$, lightening the influence bonding joint manufacturing has in the final structure strength.

In an opposite direction of investigation, Gude et al. ${ }^{11}$ studied the improvement on composite adhesively bonded structures due to the addition of carbon nanoreinforcements. The work shows the results obtained from unidirectional carbon fiber/epoxy prepregs 8552/34\%/UD134/AS4-12K from Hexcel ${ }^{\circledR}$ cured in autoclave and joined by an epoxy adhesive produced by Sigma-Aldrich ${ }^{\circledR}$. The value of $G_{I}$ for samples joined with conventional epoxy adhesive by the corrected beam theory method was $85 \mathrm{~J} / \mathrm{m}^{2}(0.085 \mathrm{~N} / \mathrm{mm})$.
On the other hand, samples made out with adhesive reinforced with carbon nanotubes was $115 \mathrm{~J} / \mathrm{m}^{2}(0.115 \mathrm{~N} / \mathrm{mm})$. The crack growth behavior also changed from stable continuous to unstable stick-slip, changing as well the failure mechanism from purely adhesive to adhesive with some areas of cohesive failure in the adhesive.

Similarly, Guo et al. ${ }^{12}$ developed a work that evaluates a method based in the integration of nylon veil surface-loaded with silver nanowires to increase both electrical conductivity and interlaminar fracture toughness of an unidirectional carbon fiber/epoxy matrix T800/5228 prepreg cured in an autoclave following manufacturer's instructions. For the control sample, with no interleaf, a $\mathrm{G}_{\mathrm{IC}}$ of $306 \mathrm{~J} / \mathrm{m}^{2}(0.306$ $\mathrm{N} / \mathrm{mm}$ ) was found.

Still analyzing the influence of the adhesive on the fracture energy release rate, Katsiropoulos et al. ${ }^{13}$ performed tests with both LMB Huntsman ${ }^{\circledR}$ and Epibond ${ }^{\circledR} 1590$ A/B adhesive and evaluated the influence of adhesive thickness in joints between AS4/8552 laminates. Surprisingly, for an adhesive thickness of $0.5 \mathrm{~mm}, \mathrm{LMB}$ presented a $\mathrm{G}_{\mathrm{I}}$ value of $250 \mathrm{~J} / \mathrm{m}^{2}(0.25 \mathrm{~N} / \mathrm{mm})$, but for a thickness of $1.5 \mathrm{~mm}$, this value decreased to $125 \mathrm{~J} / \mathrm{m}^{2}(0.125 \mathrm{~N} / \mathrm{mm})$, while the Epibond adhesive showed an enhance in the Mode I fracture toughness value from $115 \mathrm{~J} / \mathrm{m}^{2}(0.115 \mathrm{~N} / \mathrm{mm})$ to $250 \mathrm{~J} / \mathrm{m}^{2}$ $(0.25 \mathrm{~N} / \mathrm{mm})$ when its thickness is increased.

As presented, although composite laminates adhesively bonded and their fracture toughness have been largely studied, there is no consensus in the open literature about a consistent value of $\mathrm{G}_{\mathrm{I}}$ for each joining technology, once it depends on the substrate material and manufacturing process as well of the adhesive type and curing process used, besides other specimen preparation variables. As a conclusion, the results from open literature cannot be compared because the materials (both fiber and resin), specimens' dimensions and cure parameters are different from the ones used in this project.

Few studies regarding systems identical to those tested in this work were found in literature: Encinas et al. ${ }^{2}$ used a similar system, with unidirectional T800H/3900-2 prepreg from Toray $^{\circledR}$ and adhesive film EA 9696 from Henkel $^{\circledR}$ Hysols, where values around $0.6 \mathrm{~kJ} / \mathrm{m}^{2}(0.6 \mathrm{~N} / \mathrm{mm})$ were obtained for the Mode I fracture toughness, even though the bonding technique has not been defined.

Therefore, the objective of this work is to investigate the Mode I fracture toughness of two distinct joint systems applied to laminates composed of unidirectional carbon fiber T800 and epoxy matrix 3900-2C (Toray ${ }^{\circledR}$ ) with epoxy adhesive EA 9695 (Henkel $^{\circledR}$ ). For a better understanding on the failure process, adhesive from each technology was subjected to differential scanning calorimetry in order to assess possible variations in its molecular structure and the fracture surfaces of the tested samples were examined with stereoscopy and scanning electron microscopy to identify the mechanisms involved in the failure modes. 


\section{Experimental Procedures}

\subsection{Samples preparation}

Two adhesive bonding techniques are studied in this project: co-bonding $(\mathrm{CB})$ and secondary bonding $(\mathrm{SB})$. For the first one, two composite plates were manufactured with a $\left[0^{\circ}\right]_{13}$ layup, using unidirectional Toray ${ }^{\circledR}$ T800/3900-2C prepreg. One of the plates was cured in an autoclave at 177 ${ }^{\circ} \mathrm{C}$ with its surface protected with peel ply, which consists in a ply applied to the laminate surface prior cure. After that, the ply is removed, which creates a rough surface as a result of the peel ply's fibers imprints, consequently improving adhesion. To form the $\left[0^{\circ}\right]_{26}$ laminate, the cured plate and the second plate (still uncured) were bonded using the epoxy Loctite $^{\circledR}$ EA 9695 adhesive with a polyester net placed in its middle plan to maintain its thickness of $0.226 \pm 0.3 \mathrm{~mm}$ homogeneous throughout its length. A Teflon ${ }^{\circledR}$ film of 0.085 $\mathrm{mm}$ thickness and $60 \mathrm{~mm}$ length was inserted on one end of the total laminate, between the two plates, to simulate an initial crack. Finally, the entire system returned to the autoclave at $177^{\circ} \mathrm{C}$ for the cure of the adhesive.

For the second technique, two unidirectional $\left[0^{\circ}\right]_{13}$ laminate plates also made out of Toray ${ }^{\circledR}$ T800/3900-2C prepreg were cured in autoclave at $177^{\circ} \mathrm{C}$ also with the peel ply surface treatment to improve adhesion. To produce the specimens, the cured laminates were bonded together using the epoxy Loctite $^{\circledR}$ EA 9695 adhesive with $0.226 \pm 0.3 \mathrm{~mm}$ of thickness containing the polyester net. The Teflon ${ }^{\circledR}$ film of $0.085 \mathrm{~mm}$ thickness was also inserted between the two plates, in the middle of the total laminate to simulate an initial crack and the entire system returned to the autoclave to cure the adhesive accordingly to the material data sheet specifications ${ }^{14}$. Therefore, in the co-bonded laminate, only one of the $\left[0^{\circ}\right]_{13}$ laminates is post-cured, whereas in the secondary bonding, both sides are post-cured in the autoclave.

After fabricating the $\left[0^{\circ}\right]_{26}$ laminates, test samples of double cantilever beam type (DCB) with standardized dimensions of $170 \times 20 \times 5 \mathrm{~mm}$ were cut from the plates, as shows Figure 1, following the ASTM D5528-13 ${ }^{15}$ standard, to characterize the Mode I interlaminar fracture toughness.

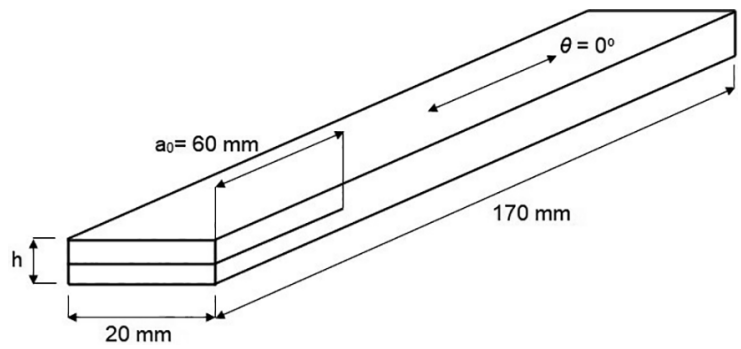

Figure 1. DCB specimens dimensions for Mode I interlaminar fracture toughness tests. $\mathrm{h}=5 \mathrm{~mm}$ for all samples

\subsection{Mode I fracture toughness characterization}

The crack propagation was measured using a high definition camera with macro lens attached to it. The samples were white painted on both sides in order to enhance the crack tip visualization. Vertical lines were drawn every $1 \mathrm{~mm}$ from the end of the Teflon ${ }^{\circledR}$ insert, where the delamination process should start, until $50 \mathrm{~mm}$ and then after every $5 \mathrm{~mm}$ for the following $30 \mathrm{~mm}$.

For all tests, aluminum loading blocks were used to apply the load in the samples. Each block was bonded with epoxy adhesive in the specimens' ends where the Teflon ${ }^{\circledR}$ insert was placed.

The samples were then attached to an Instron ${ }^{\circledR} 5500 \mathrm{R}$ testing machine (Figure 2) with a loading cell of $2 \mathrm{kN}$. The load was applied with a constant displacement rate of $1 \mathrm{~mm} / \mathrm{min}$. The tests were conducted at $25^{\circ} \mathrm{C}$ and relative humidity of $50 \%$.

The delamination extension as a function of the applied load was registered using a crack marker that was pressed every time the crack crossed one of the vertical marks made in the lateral of the samples, which was observed with an Imetrum ${ }^{\circledR}$ Video Gauge 3.0 camera placed in front of the test.

The energy release rate expression, given by Equation (1), is obtained from the beam theory for a double cantilever beam, considering the correction factors for both rotation at the delamination front and large displacement effects ${ }^{15,16}$ :

$$
G_{I}=\frac{3 P \delta F_{c}}{2 w(a+|\Delta|)}
$$

where $P$ is the applied load, $\delta$ corresponds to the transversal displacement where the load is applied, $a$ is the crack length, $w$ is the sample width, $\Delta$ is the correction for the rotation that may occur at the delamination front and $F_{c}$ is the correction factor for large displacements ${ }^{15}$.

\subsection{Stereoscopic analysis}

Looking for a better understanding of the failure process on each specimen, the surfaces were examined with a Olympus $^{\circledR}$ Infinity SZ 61 stereoscope, with 110AL2X-2 WD38 lens and SZ2-LGB lighting system with a LED lamp of $3290 \mathrm{~K}\left(\right.$ Olympus $\left.^{\circledR}\right)$.

\subsection{Fractographic analysis}

Stereo microscopes are not always the most appropriate equipments to study fracture surfaces. In those cases, Scanning Electron Microscopy (SEM) must be used to achieve a satisfactory magnification when analyzing a fracture process. A Vega3 Tescan ${ }^{\circledR}$ system was used. The samples required cleaning in an ultrasonic bath and drying before being sputtered with a thin gold layer by a Q150R Quorum ${ }^{\circledR}$ coating system. After this preparation, the samples could be investigated. 

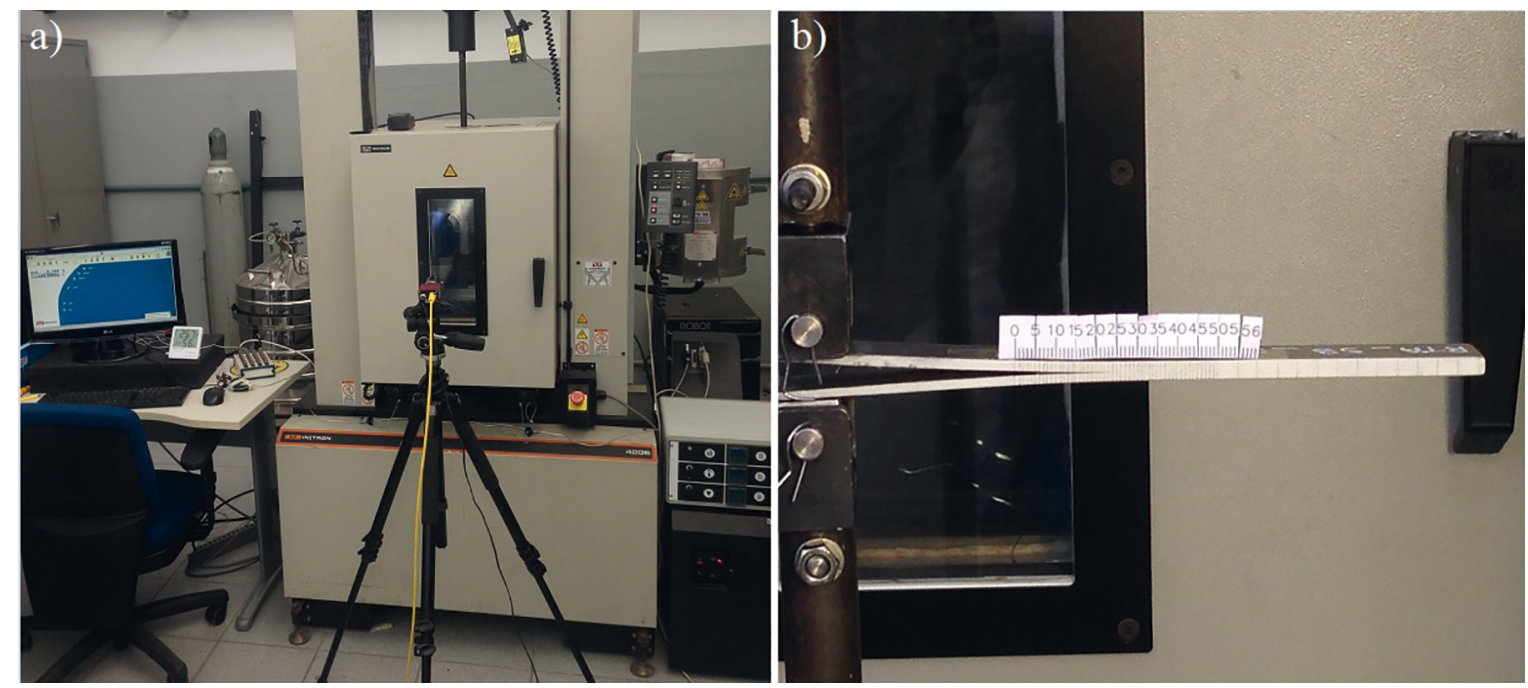

Figure 2. a) Experimental apparatus used for the Mode I interlaminar fracture toughness characterization; b) Specimen attached to the machine by the loading blocks

\subsection{Differential scanning calorimetry}

For a deeper understanding on the molecular differences between each bonding technology, Differential Scanning Calorimetry (DSC) was performed to assess the glass transition temperature of the adhesive used in each one. Approximately $3.5 \mathrm{mg}$ of granular samples collected from tested specimens were tested in a PerkinElmer ${ }^{\circledR}$ Pyris 1 DSC equipped with a PerkinElmer Intracooler $2 \mathrm{P}$ cooling device with a purge rate of nitrogen of $20 \mathrm{~cm}^{3} / \mathrm{min}$ at a heating rate of $10^{\circ} \mathrm{C}$ from $20^{\circ} \mathrm{C}$ to $350^{\circ} \mathrm{C}$.

\section{Results and Discussion}

In total, sixteen samples were tested (eight for each technology). During the mechanical tests, stick-slip behavior was observed in CB technology, which is a phenomenon characterized by regions of almost no crack growth as the load increases and, reaching a critical energy release rate value, crack propagates unstably and the load drops unexpectedly ${ }^{8}$, which leaves a very well-defined pattern on the fracture surface, as shows Figure 3.a.

The regions where almost no crack growth was observed are seen as the thin light-gray vertical stripes that separate the dark-gray regions where unstable propagation occurred. In the case of SB samples, after the first length of unstable propagation (dark-gray area), the remaining length experienced a crack growing stably (light-gray area), as can be seen in Figure 3.b. Figure 3 also correlates each fracture surface with the corresponding Load versus Crack length curve. The red lines relate how far the crack propagated (unstably) when the drop in load happened. For each peak, the correspondent region where crack remained almost completely stagnated while the load increased is the light-gray stripe that precedes the dark-gray region of unstable propagation.
The stick-slip behavior can be explained as a result of a plastic region formation in the crack tip just after the unstable growth. A slow propagation is observed while the crack stays inside this region, which is followed by a rupture where the crack rapidly enters the "virgin" material region that was not affected until then ${ }^{17}$. In Figure 3, the stable propagation regions are evident as they present a lighter color than the unstable regions.

The Mode I propagation fracture toughness values are presented as a function of crack length on Figure 4 for both bonding techniques. These values were obtained using the Modified Beam Theory Method ${ }^{6,15}$ (Eq. 1). The initiation values were obtained by visual observation (VIS) ${ }^{15}$, which accordingly to Blackman et al. ${ }^{6}$, presents values between the most and the less conservative methods for determining $\mathrm{G}_{\mathrm{IC}}$ (deviation from linearity $(\mathrm{NL})$ and $5 \%$ offset/maximum load (5\%/Max), respectively).

In Figure 4.a, it can be seen that the fracture toughness mean values obtained from the arrest phase for co-bonded specimens varies between $0.3 \mathrm{~N} / \mathrm{mm}$ in the beginning of propagation, with a larger standard deviation, to $0.25-0.2 \mathrm{~N} /$ $\mathrm{mm}$ at the end of propagation, with much lower deviation. For the secondary bonding (Figure 4.b), however, the standard deviation remains practically the same for all crack lengths with fracture toughness mean values varying more in comparison to co-bonded results, even though the initial and final values of $\mathrm{CB}$ and $\mathrm{SB}$ are almost equal. Table 1 shows the initiation, $\mathrm{G}_{\mathrm{IC}}$, and propagation (all other values with exception to the initiation one), $\mathrm{G}_{\mathrm{Ip}}$, fracture toughness values for co-bonded and secondary bonded samples with their respective standard deviation.

Even though stick-slip occurs in co-bonded samples only, this behavior did not affect in a relevant manner the mean values of fracture toughness compared to the secondary 
a)
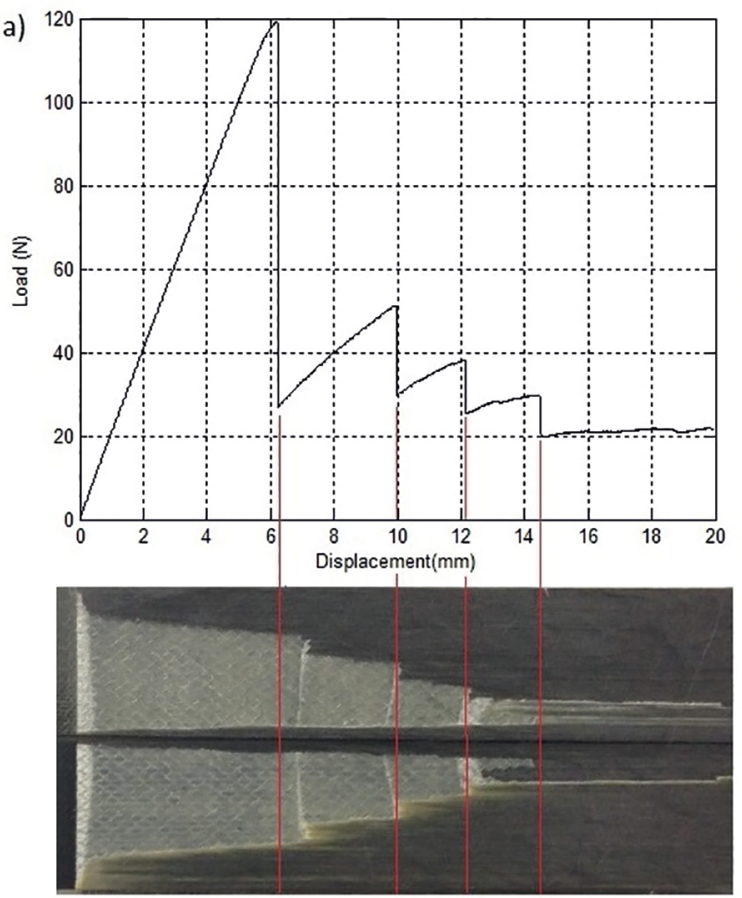

b)
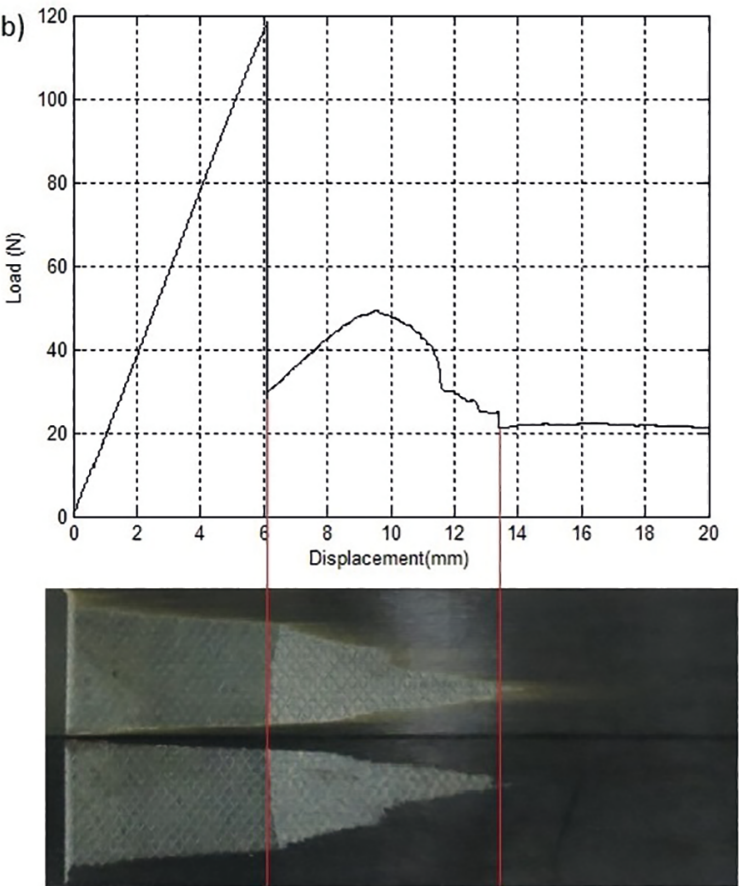

Figure 3. Load versus Crack Length curves correlated to the tested specimens fracture surfaces. a) co-bonded; b) secondary bonding

\section{a)}
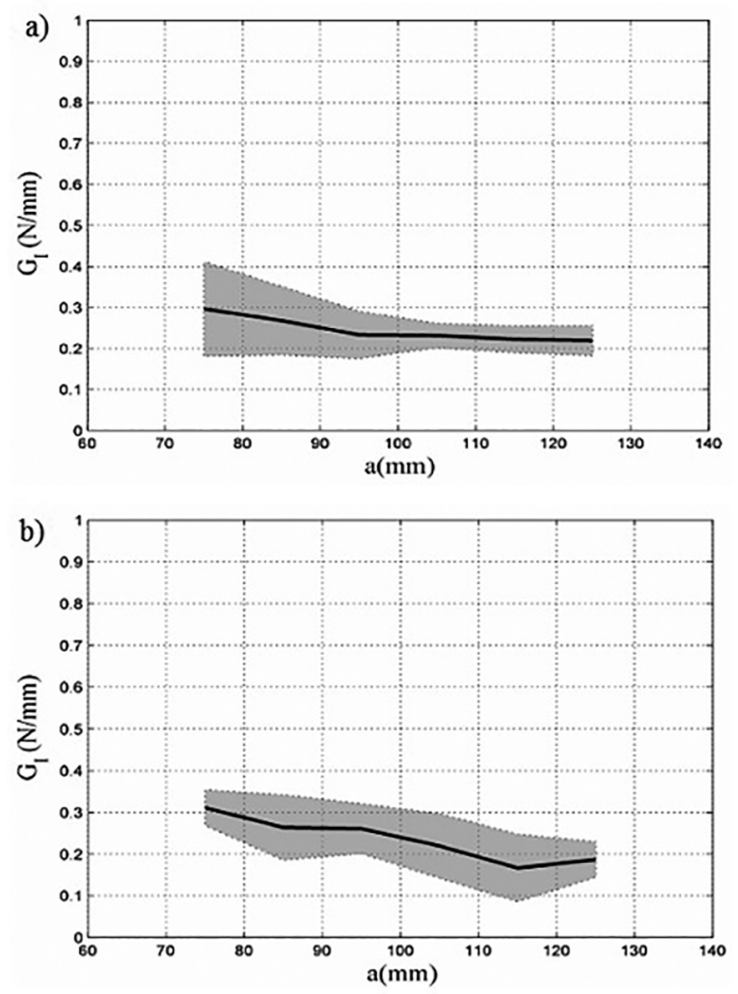

Figure 4. a) Mode I fracture toughness of co-bonded joints; b) Mode I fracture toughness of secondary bonded joints. The black line corresponds to the mean fracture toughness and the shaded area corresponds to the standard deviation
Table 1. Pure Mode I initiation $\left(\mathrm{G}_{\mathrm{IC}}\right)$ and propagation $\left(\mathrm{G}_{\mathrm{Ip}}\right)$ fracture toughness values of co bonding and secondary bonding techniques.

\begin{tabular}{lcc}
\hline $\begin{array}{l}\text { Bonding } \\
\text { Technology }\end{array}$ & $\mathbf{G}_{\text {IC }}[\mathbf{N} / \mathbf{m m}]$ & $\mathbf{G}_{\text {Ip }}[\mathbf{N} / \mathbf{m m}]$ \\
\hline Co-bonding & $0.158 \pm 0.026$ & $0.235 \pm 0.048$ \\
Secondary bonding & $0.191 \pm 0.093$ & $0.220 \pm 0.068$ \\
\hline
\end{tabular}

bonded ones, what makes both technologies very similar if compared quantitatively. However, because stick-slip consists of a sequence of rapid, unexpected propagation phases, its presence is not desirable for a project, making secondary bonding a better technology to be applied in the structure.

It is observed from Figure 4 that the dispersion is greater in the beginning of the propagation for the co-bonded technology, becoming more homogeneous and less sparse from a crack length of $105 \mathrm{~mm}$, whereas for secondary bonding, standard deviation is practically constant along the propagation. This fact is related to the failure locus: as crack leaves the adhesive and migrates to the substrate, it is observed that propagation tends to become more stable and fracture toughness decreases. This difference experienced by fracture toughness that is related to the failure locus is reported by other authors, where cohesive failure presents a higher energy release rate than interlaminar failure ${ }^{18}$.

Only articles that analyzed secondary bonding technology were found in the open literature. Blackman et al. ${ }^{6}$ found more conservative values of $G_{I}\left(151 \mathrm{~J} / \mathrm{m}^{2}(0.151 \mathrm{~N} / \mathrm{mm})\right.$ 
for initiation and $208 \mathrm{~J} / \mathrm{m}^{2}(0.208 \mathrm{~N} / \mathrm{mm})$ for propagation) for a IM7/977-2 laminate, while Ashcroft, Hughes and Shaw $^{8}$ and Moura, Campilho and Gonçalves ${ }^{9}$ obtained values above those calculated here, between 400-600 J/m² $(0.4-0.6 \mathrm{~N} / \mathrm{mm})$ during the unstable propagation stage for a graphite fiber BMI/epoxy system and $0.4 \pm 0.02 \mathrm{~N} / \mathrm{mm}$ for a Texipreg HS 160 RM system, respectively. Meanwhile, Guo et al. ${ }^{12}$ found values of $\mathrm{G}_{\mathrm{IC}}$ around $306 \mathrm{~J} / \mathrm{m}^{2}(0.306 \mathrm{~N} /$ $\mathrm{mm}$ ) from the reference tests on unidirectional carbon fiber/ epoxy matrix T800/5228 prepregs. These works show that even with some variation, the results obtained herein are in the same order of magnitude for carbon/epoxy composites adhesively bonded tested worldwide, validating the current methodology.

Figure 5 shows stereoscopic images of the surface areas of more interest for study. Thus, regions from the beginning of propagation and regions where the transition between cohesive and interlaminar failure occurs are presented.

Figures 5.a.A and 5.b.C were made at the insert/first crack propagation border region. Figures 5.a.B and 5.b.D were made at the border between cohesive and intralaminar failure in the composite. During cohesive failure, the polyester net placed in the adhesive middle can be seen in detail.

The similarity between Figures 5.a.A and 5.b.C indicates that the beginning of propagation occurred in a similar manner for both technologies, starting with cohesive failure (which can also be observed by maximum point of stick-slip in Figure 3, where the maximum load and drop of load are practically equal), corresponding to the first stage of delamination. The first high peak, common to both technologies, might be a result of a resin pocket in front of the insert, which holds the crack propagation until a critical value is achieved. On the other hand, Figures 5.a.B and 5.b.D show three different regions: dark-gray region of cohesive failure, where unstable propagation happened; light-gray region, also of cohesive failure, where stable propagation happened; and adhesive/ intralaminar failure, where the yellow color of the adhesive and substrate fibers can is observed, corresponding to the second stage of delamination.

However, notice that these figures differ because in Figure 5.a.B, the stable propagation area is limited to a small stripe, while in Figure 5.b.D it extends for all the remaining length. Propagation also becomes more stable as the failure changed from cohesive to adhesive and then intralaminar, finally becoming completely interlaminar, progressing in the substrate, where the third and final stage of delamination occurs.

As microscopy made with stereo microscope could not address conclusive images, SEM analysis was performed. Figure 6 brings fractographic images of the most interesting areas. Figures 6.a and 6.c show regions where the separation between unstable and stable propagation occurred, while Figures 6.b and 6.d show the transition from cohesive to interlaminar failure.
As seen from Figure 3, the larger the region of interlaminar failure, the lower maximum load magnitude. This transition caused a consequent diminish in the value of fracture toughness, once substrate was found to be the path of lower energy for the propagation ${ }^{18}$. From fractographies presented in Figures 6.b and 6.d, it is possible to see crack growing from cohesive region (first stage of propagation), crossing the most superficial resin layer that covers substrate, where microcracks and scarps (tradicional fractographic features from Mode I failure) are observed (second stage of propagation), before finally reaching substrate and starts to propagate among fibers (interlaminar and third stage of propagation).

From Figures 6.a and 6.c, for both CB and SB samples it is possible to see that where stable crack growth happened, a more deformed surface can be seen, corresponding to the light-gray areas previously observed, while unstable propagation resulted in a featureless surface, with almost no deformation, corresponding to the dark-gray regions. This evidence corroborates the explanation for the stickslip mechanism, with crack tip blunting and formation of a plastic region ahead of it, but it cannot explain the different behavior between $\mathrm{CB}$ and $\mathrm{SB}$, that has not presented stickslip, even though both technologies seem to be very similar to one another.

Hunt, Kratz and Partridge ${ }^{19}$ related the stick-slip behavior with the transition from cohesive to interlaminar failure modes by subjecting a Hexply ${ }^{\circledR}$ prepreg to different curing paths. In the work, the laminates submitted to a cure temperature above the standard one $\left(180^{\circ} \mathrm{C}\right)$ presented unstable propagation during testing, while the samples that stayed below this temperature propagated stably. Comparing their results with the ones presented on this paper, the secondary bonded samples behaved alike the samples cured at temperatures under $180{ }^{\circ} \mathrm{C}$, presenting a short length of stick-slip and then continuing with stable propagation for the rest of the test. On the other hand, the co-bonded specimens resemble those samples cured at the standard temperature, where the stick-slip phenomenon is much more present.

Such observation suggests that a possible explanation for the different behaviors between technologies is hidden in the fact that on the secondary bonding technique, both laminates were submitted to a post-cure process (first cure for the fabrication of the plates and second to cure the adhesive), while the co-bonded had only one of the laminates being in the autoclave twice.

To assess this hypothesis, adhesive samples collected from both bonding technologies specimens after static tests were submitted to DSC. The main objective here is to obtain the glass transition temperature ( $\mathrm{Tg}$ ) of the adhesive from each technology and verify if there are differences between both. As glass transition temperature is the temperature at which polymer chains have mobility to move relatively to each other, $\mathrm{Tg}$ also reflects the molecular structure of 

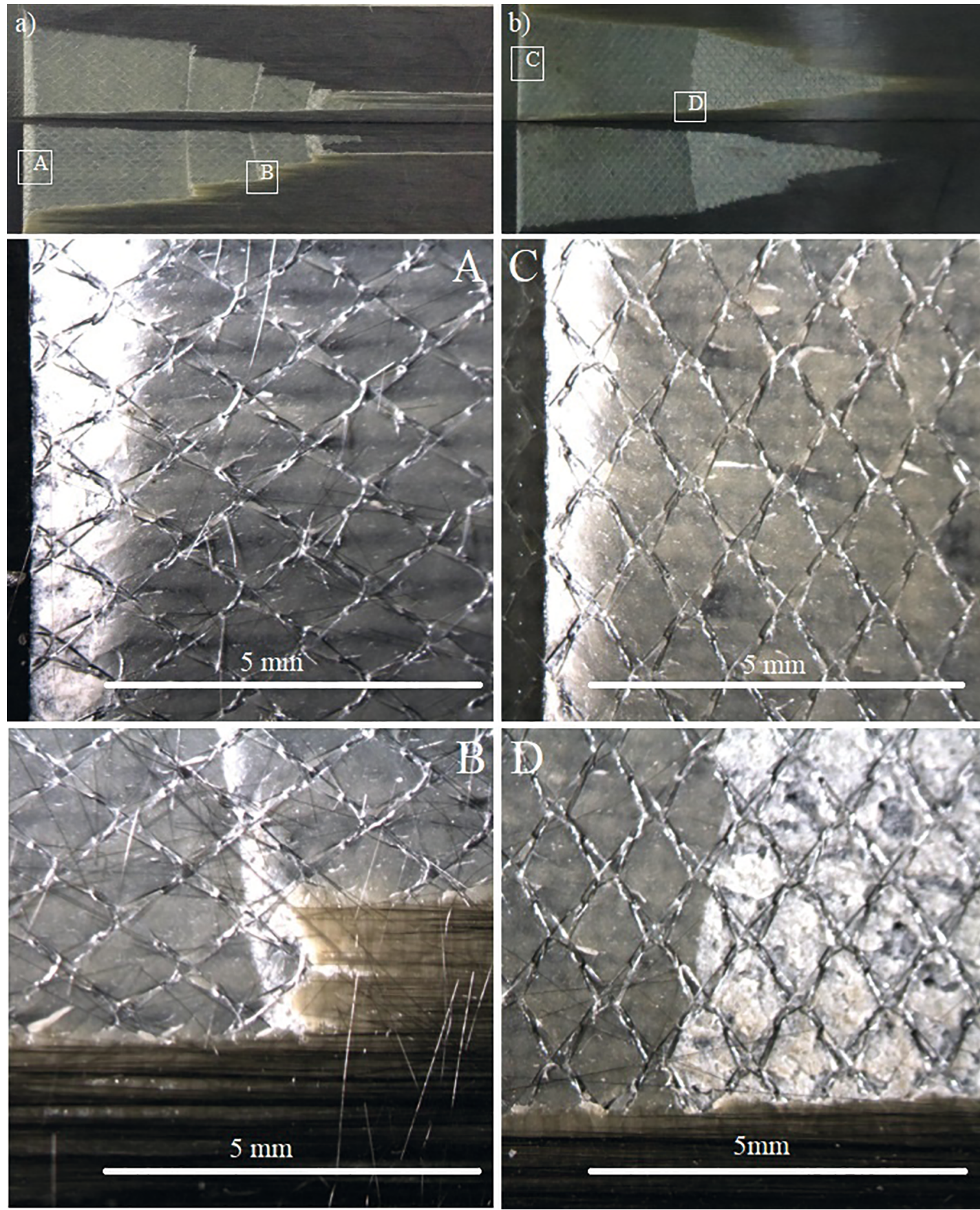

Figure 5. Samples stereoscopies: a) co-bonded; b) secondary bonding. Magnification of $1.5 \mathrm{x}$

materials ${ }^{20}$. Following ASTM Standard D3418 ${ }^{21}$, Tg is at half-height between DSC curve baseline and the plateau after shifting. This step is a result of the difference in heat capacity that accompanies glass transition. Sometimes, it is easier to identify the curve shift using the derivative of heat flow versus temperature curves, where glass transition become the peak of this new curve. Figure 7 shows the derivative of heat flow versus temperature for $\mathrm{CB}$ and SB samples.
From DSC analysis, values of $105.24 \pm 4.31^{\circ} \mathrm{C}$ and $113.57 \pm 11.78^{\circ} \mathrm{C}$ were obtained for the adhesive collected from $\mathrm{CB}$ and SB samples, respectively. It may not be a considerably difference, but it can show a trend where $\mathrm{SB}$ technology results in adhesive with higher cross-linking density during cure process compared to $\mathrm{CB}$, which leads to a lower chain mobility and, consequently, higher glass transition temperature. 

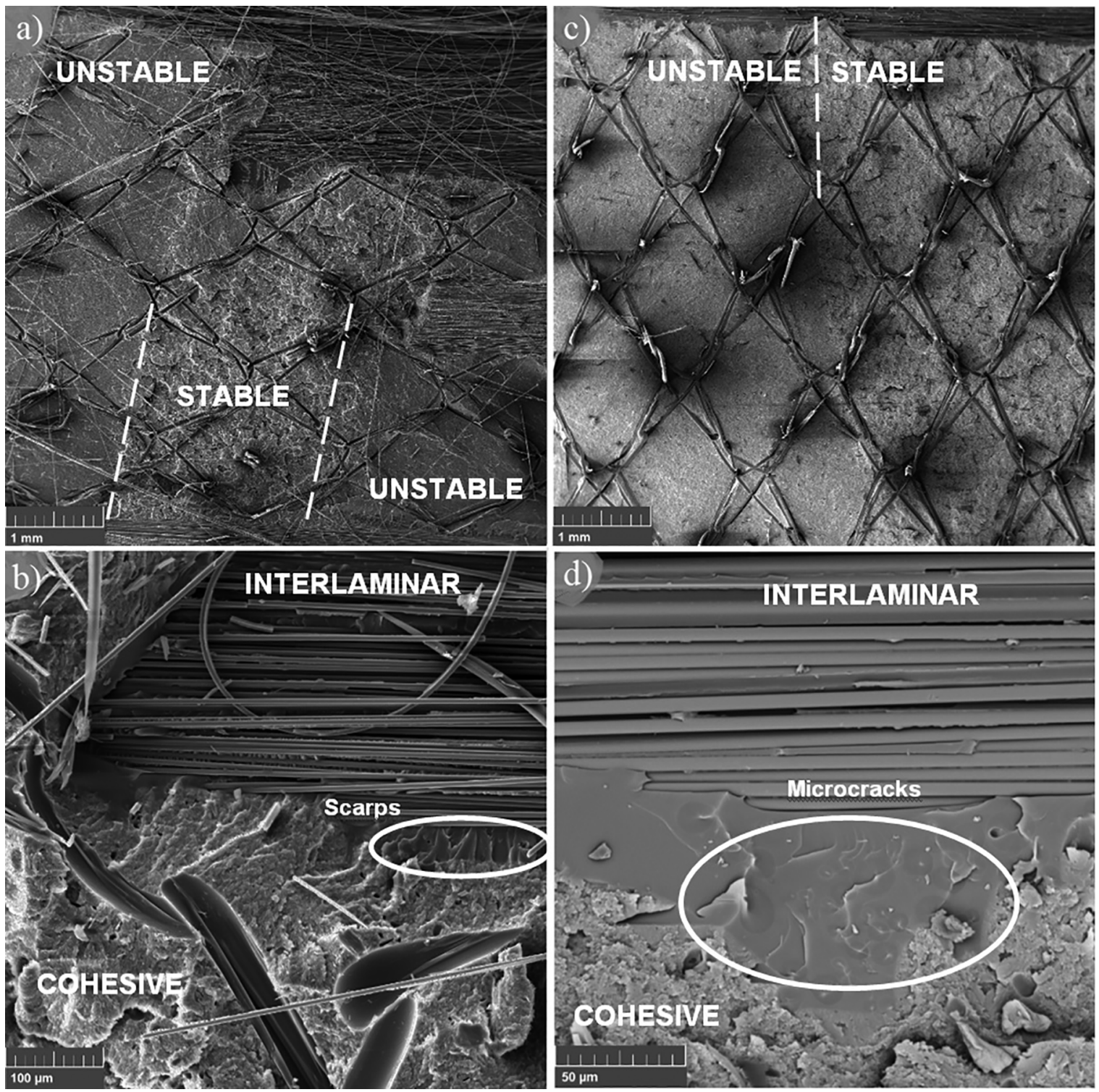

Figure 6. SEM images of: $a$ and b) co-bonded; $c$ and d) secondary bonding specimens. Magnification of 50x, 500x, 50x and 1000x, respectively
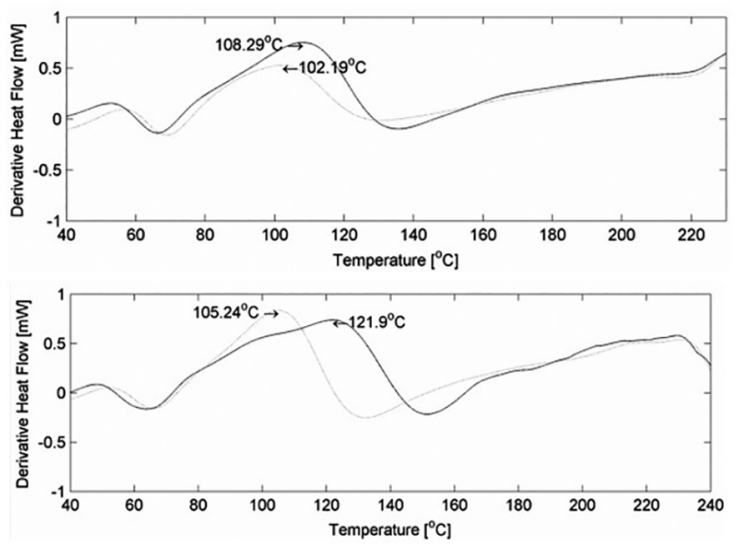

This difference in glass transition temperature between the bonding technologies can be responsible for the differences that occurred during their mechanical tests. The lower $\mathrm{Tg}$ observed for CB adhesive could be explained by the fact that uncured materials contain free and bound water (the first bonds with resin by one single hydrogen bond whereas the second bonds by multiple hydrogen bonds ${ }^{4,22}$ ), which is released during cure process. SB has only the water from the adhesive to be released, while $\mathrm{CB}$ still has an uncured laminate to be cured. This additional released water from the uncured laminate could act as a plasticizer in the adhesive and, then, contributes to the lower glass transition temperature reported herein $^{22,23}$ and, consequently, to the difference behavior.

Figure 7. Derivative of heat flow versus temperature curves of: top) co-bonded; bottom) secondary bonding specimens 


\section{Conclusions}

For a better understanding of the failure modes on composite joints produced by co-bonding and secondary bonding techniques, the Mode I fracture toughness was investigated. The $\mathrm{G}_{\mathrm{I}}$ values obtained from the co-bonded specimens present a slightly lower standard deviation along the propagation length than those obtained from the secondary bonding tests, but secondary bonding presented a more stable propagation during the tests, which is a more desirable behavior in terms of project, as stick-slip can be more difficult to predict.

Microscopy was applied to clarify the fracture mechanisms. Three distinct zones could be observed for both technologies, each one associated to stages obtained during the mechanical tests: $1^{\text {st }}$ elevated initiation energy and unstable crack propagation (mainly cohesive failure, inside the adhesive); $2^{\text {nd }}$ crack grows with an energy lower than the one from initiation (transition from cohesive to adhesive during a very short length, soon becoming intralaminar); and $3^{\text {rd }}$ the energy decreases considerably and propagation is completely stable (delamination continues as interlaminar, continuing inside the substrate). Besides that, fractography allowed the confirmation of the hypothesis that explained the stick-slip mechanism, where the small region related to the arrest phases showed a more rough surface due to the plastic deformation in that area in comparison to the larger dark areas of fast propagation, with a more smooth aspect.

To evaluate the reason that led to different behavior between $\mathrm{CB}$ and $\mathrm{SB}$, glass transition temperature of adhesives obtained from each technology was assessed using DSC technique. After the test, it was obtained a trend where CB presents lower Tg than $\mathrm{SB}$, which can be a result of the inherent moisture present in the uncured laminate that is released during cure, consequently causing some plasticization effect in the adhesive.

\section{Acknowlegments}

The main author has a scholarship provided by the Coordination for the Improvement of Higher Education Personnel (Capes Demanda Social - 1543373). This project is partially supported by the National Council for Scientific and Technological Development (CNPq), processes 155963/2014-7, 154974/2015-3, 300893/2015-9 and 300990/2013-8, Funding Authority for Studies and Projects (FINEP), process 0114018300 and the São Paulo Research Foundation (FAPESP), process 2015/16733-2.

\section{References}

1. Noor AK, Venneri SL, Paul DB, Hopkins MA. Structures technology for future aerospace systems. Computers \& Structures. 2000;74(5):507-519.

2. Encinas N, Oakley BR, Belcher MA, Blohowiak KY, Dillingham RG, Abenojar J, et al. Surface modification of aircraft used composites for adhesive bonding. International Journal of Adhesive and Adhesives. 2014;50:157-163.
3. Balzani C, Wagner W, Wilckens D, Degenhardt R, Busing S, Reimerdes HG. Adhesive joints in composite laminates - A combined numerical/experimental estimate of critical energy release rates. International Journal of Adhesive and Adhesives. 2012;32:23-28.

4. Mohan J, Ivankovic A, Murphy N. Mixed-mode fracture toughness of co-cured and secondary bonded composite joints. Engineering Fracture Mechanics. 2015;134:148-167.

5. Sarrado C, Turon A, Costa J, Renart J. On the validity of linear elastic fracture mechanics methods to measure the fracture toughness of adhesive joints. International Journal of Solids and Structures. 2016;81:110-116.

6. Blackman BK, Kinloch AJ, Paraschi M, Teo WS. Measuring the mode I adhesive fracture energy, GIC, of structural adhesive joints: the result of an international round-robin. International Journal of Adhesion and Adhesives. 2003;23(4):293-305.

7. Blackman BRK, Kinloch AJ, Paraschi M. The effect of the substrate material on the value of the adhesive fracture energy, Gc: Further considerations. Journal of Materials Science Letters. 2001;20(3):265-267.

8. Ashcroft IA, Hughes DJ, Shaw SJ. Mode I fracture of epoxy bonded composite joints: 1. Quasi-static loading. International Journal of Adhesion and Adhesive. 2001;21(2):87-99.

9. De Moura MFSF, Campilho RDSG, Gonçalves JPM. Crack equivalent concept applied to the fracture characterization of bonded joints under pure mode I loading. Composites Science and Technology. 2008;68(10-11):2224-2230.

10. Markatos DN, Tserpes KI, Rau E, Markus S, Ehrhart B, Pantelakis $\mathrm{S}$. The effects of manufacturing-induced and in-service related bonding quality reduction on the mode-I fracture toughness of composite bonded joints for aeronautical use. Composites Part B: Engineering. 2013;45(1):556-564

11. Gude MR, Prolongo SG, Gómez-del Río T, Ureña A. Mode-I adhesive fracture energy of carbon fibre composite joints with nanoreinforced epoxy adhesives. International Journal of Adhesive and Adhesives. 2011;31(7):695-703.

12. Guo M, Yi X, Liu G, Liu L. Simultaneously increasing the electrical conductivity and fracture toughness of carbon-fiber composites by using silver nanowires-loaded interleaves. Composites Science and Technology. 2014;97:27-33.

13. Katsiropoulos CV, Chamos AN, Tserpes KI, Pantelakis SG. Fracture toughness and shear behavior of composite bonded joints based on a novel aerospace adhesive. Composites Part B: Engineering. 2012;43(2):240-248.

14. Henkel. Loctite EA 9695 AERO (Hysol EA 9695). Available from: <http://na.henkel-adhesives.com/product-search-1554. htm? nodeid $=8806582550529>$. Access in: 04/01/2018.

15. ASTM International. ASTM D5528-13 - Standard Test Method for Mode I Interlaminar Fracture Toughness of Unidirectional Fiber-Reinforced Polymer Matrix Composites. West Conshohocken: ASTM International; 2013.

16. Cândido GM, Rezende MC, Donadon MV, Almeida SFM. Fractografia de compósito estrutural aeronáutico submetido à caracterização de tenacidade à fratura interlaminar em modo I. Polímeros. 2012;22(1):41-53. 
17. Yamini S, Young RJ. The mechanical properties of epoxy resins - Part 2 Effect of plastic deformation upon crack propagation. Journal of Materials Science. 1980;15(7):1823-1831.

18. Costa J, Renart J, Batista Y, Mahdi S, Rodríguez-Bellido A. Detailed investigation of bonded joints for composite repairs. In: Proceedings of $18^{\text {th }}$ International Conference on Composite Materials; 2011 Aug 21-26; Jeju Island, South Korea.

19. Hunt C, Kratz J, Partridge IK. Cure path dependency of Mode I fracture toughness in thermoplastic particle interleaf toughened prepreg laminates. Composites Part A: Applied Science and Manufacturing A. 2016;87:109-114.

20. Menard K. Dynamic Mechanical Analysis: A Practical Introduction. Boca Raton: CRC Press; 2008.
21. ASTM International. ASTM D3418-15 - Standard Test Method for Transition Temperatures and Enthalpies of Fusion and Crystallization of Polymers by Differential Scanning Calorimetry. West Conshohocken: ASTM International; 2015.

22. Mohan J, Ivankovic A, Murphy N. Effect of prepreg storage humidity on the mixed-mode fracture toughness of a co-cured composite joint. Composites Part A: Applied Science and Manufacturing A. 2013;45:23-34.

23. Budhe S, Banea MD, Barros S, Silva LFM. An updated review of adhesively bonded joints in composite materials. International Journal of Adhesion and Adhesives. 2017;72:30-42. 